$(\mathrm{N}=27 ; \mathrm{p}=0.023)$. Significant increases in QoL $(\mathrm{p}=0.002)$ were also found on the Juniper QoL. FEV 1 significantly improved with a mean score of 2.21 at baseline, increasing to 2.83 at one-year $(\mathrm{p}<0.001)$. Multiple regressions showed that $25 \%$ of the variance in QoL was predicted by $\mathrm{FEV}_{1}$; however, depression and $\mathrm{FEV}_{1}$ combined explained $50.8 \%$ of the variance $(\mathrm{p}<0.001)$.

Conclusions Multidisciplinary intervention led to effective improvement in well-being and lung function in patients with severe and difficult asthma. The improvements in QoL were predicted by both $\mathrm{FEV}_{1}$ and depression. We recommend supporting patients' adaptation to life with severe asthma as an integrated function of the multidisciplinary approach. This approach can help minimise anxiety and depression symptoms, improve QoL and reduce the psychological impact upon physical symptoms.

\begin{tabular}{|c|c|c|c|}
\hline & $\begin{array}{l}\text { Baseline } \\
\text { (Mean Score) }\end{array}$ & $\begin{array}{l}\text { One-Year Assessment } \\
\text { (Mean Score) }\end{array}$ & $\begin{array}{l}\text { P Value } \\
{ }^{*}=\text { significant }\end{array}$ \\
\hline HADS Depression & 7.69 & 7.13 & .192 \\
\hline HADS Anxiety & 8.97 & 7.56 & $.023^{*}$ \\
\hline AQLQ (Juniper QoL) & 3.20 & 4.09 & $.002^{*}$ \\
\hline $\mathrm{FEV}_{1}$ & 2.21 & 2.83 & $.000^{*}$ \\
\hline
\end{tabular}

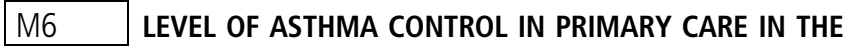 UK AS DETERMINED BY THE RCP 3 QUESTIONS}

J Fettiplace, S Jogee, N Rajakumaraswamy; GlaxoSmithKline UK, London, UK

10.1136/thoraxjnl-2013-204457.416

Introduction From 2012, the Quality Outcomes Framework (QOF) in Asthma was amended to include an objective assessment of a patient's asthma control using the RCP 3 questions.

In the last month

- Have you had difficulty sleeping because of your asthma symptoms (including cough)?

- Have you had your usual asthma symptoms during the day (cough, wheeze, chest tightness or breathlessness)?

- Has your asthma interfered with your usual activities (for example, housework, work/school, etc.)?

Controlled asthma is defined as answering 'no' to all 3 questions.

Cegedim Ltd, who own the InPS Vision prescribing software, have access to anonymised QOF data and have used 150 GP practices which are selected to provide UK-wide representation. This has enabled an analysis to determine real-world levels of asthma control in primary care in the UK.

Methods Asthma patients were identified according to QOF business rules. Patients who had provided responses to the RCP 3 questions (during the period March 2012-February 2013) were selected. A subset of those who had been on the same medication for the 12 months prior to that assessment were specified, defined as consistently prescribed the same medication at the time of assessment and 12 months prior.

Results A cohort of 19,582 asthma patients who had completed the RCP 3 question assessment during the study period with 12 months of consistent therapy was identified. One-quarter $(25 \%)$

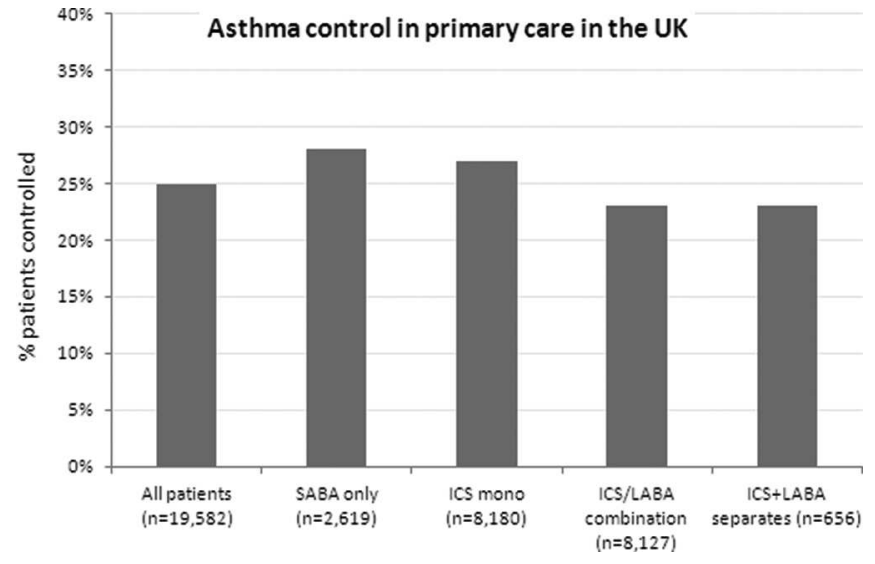

Abstract M6 Figure 1.

of patients were controlled (answered 'no' to all questions). For patients at BTS Step 1 (SABA only) and BTS Step 2 (ICS monotherapy), the proportion controlled was $28 \%$ and $27 \%$ respectively. For patients at BTS Step 3 and above (ICS and LABA in combination, including as separate inhalers) the proportion was $23 \%$ (see figure).

Conclusions Asthma control in primary care in the UK is poor with only $25 \%$ of asthmatics achieving control as defined by the RCP 3 questions; levels of control were consistent across BTS steps. Interventions to understand barriers and improve asthma control are warranted.

\section{M7 POOR CONTROL OF ASTHMA IN UYO, SOUTH-EASTERN NIGERIA}

VA Umoh, I lbok; University of Uyo Teaching Hospital, Uyo, Nigeria

\subsection{6/thoraxjnl-2013-204457.417}

Background The prevalence of asthma is increasing in the developing world. Asthma, management guidelines have been instituted to provide recommendations for the optimal control of asthma. This study evaluated the current level of asthma control as reported by the patients which may be a reflection of adherence to guidelines.

Methods Asthma patients referred to a respiratory diseases clinic were recruited for the study. The asthma control test (ACT) was administered on the patients. Data was also obtained for medication use and disease monitoring. A total ACT score of less than 20 signified poor control.

Results Seventy out of 78 patients completed the survey (89.7\%). The average age of patients was $46 \pm 18$ years. The average ACT score was $14.4 \pm 4.8$ (mean $\pm \mathrm{SD}$ ). $82.9 \%$ of patients had poor control. $57.1 \%$ of patients who perceived their asthma to be well or totally controlled were objectively assessed to be poorly controlled. More than half of the patients used short acting $\beta 2$ agonist (SABA) alone and only 20\% used inhaled corticosteroids (ICS) for maintenance therapy. Thirty eight patients made unscheduled emergency room visits in the past 12 months and $68.8 \%$ could not use their inhaler devises well. Emergency room visits (OR 9.5) and poor inhaler technique (OR 18.9) was independent predictors of poor asthma control.

Conclusion The current level of asthma control among patients in Uyo is below guideline recommendations. Management of patients did not appear to follow guideline recommendations and patients tend to over-estimate their disease control. 


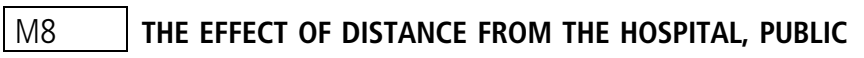
TRANSPORT AVAILABITY AND SOCIOECONOMIC DEPRIVATION ON NON-ATTENDANCE AT A DIFFICULT ASTHMA CLINIC

${ }^{1} \mathrm{~J}$ Mayer, ${ }^{2} \mathrm{P}$ Abraham, ${ }^{1} \mathrm{H}$ Burhan, ${ }^{1} \mathrm{BJ}$ McDonough, ${ }^{1} \mathrm{~S}$ Mault; ${ }^{1}$ Royal Liverpool University Hospital, Liverpool, United Kingdom; ${ }^{2}$ College of Medicine - University of Malawi, Blantyre, Malawi

\subsection{6/thoraxjnl-2013-204457.418}

Introduction Regular clinic review is an important factor in reducing morbidity in asthma ${ }^{1}$. In a specialist difficult asthma clinic at our large city centre teaching hospital seeing more than 100 new primary and secondary care referrals per year, 'did not attend' (DNA) rates were 9\% higher than in a general respiratory clinic led by the same consultant. A previous study has demonstrated an association between socioeconomic deprivation and non-attendance ${ }^{2}$. We hypothesised distance from the clinic, long public transport journeys and socioeconomic deprivation were related to an increased number of missed appointments.

Methods Data were collected between April 2011 and March 2012 inclusive. Patient criteria included those with a Liverpool postcode who had missed one or more of their appointments. Patients were grouped into categories according to number of DNAs. Distance from hospital; availability and time taken by public transport and socioeconomic status of postcode were reviewed. These were calculated using Google maps; local public travel information services and the Indices of Deprivation 2010 dataset $^{3}$.

\begin{tabular}{|c|c|c|c|c|}
\hline $\begin{array}{l}\text { No. of } \\
\text { DNAs }\end{array}$ & $\begin{array}{l}\text { No. of } \\
\text { patients }\end{array}$ & $\begin{array}{l}\text { Mean distance } \\
\text { from hospital } \\
\text { in miles } \\
\text { (Standard } \\
\text { Deviation) }\end{array}$ & $\begin{array}{l}\text { Mean time } \\
\text { taken by } \\
\text { public transport } \\
\text { in minutes } \\
\text { (Standard } \\
\text { Deviation) }\end{array}$ & $\begin{array}{l}\text { Mean Index of } \\
\text { Deprivation }{ }^{1} \\
\text { (Standard } \\
\text { Deviation) }\end{array}$ \\
\hline 1 & 55 & 3.09 (1.64) & 28.69 (10.79) & $5250(6477)$ \\
\hline 2 & 20 & $3.44(2.41)$ & $27.45(12.53)$ & 3554 (5465) \\
\hline 3 & 9 & $3.78(3.70)$ & $27.00(14.27)$ & 3427 (4007) \\
\hline 4 & 3 & $4.00(0.59)$ & $14.00(6.24)$ & $402(519)$ \\
\hline 5 & 1 & N/A & N/A & $\mathrm{N} / \mathrm{A}$ \\
\hline 6 & 1 & $N / A$ & N/A & N/A \\
\hline$p$ value & & 0.70 & 0.20 & 0.39 \\
\hline
\end{tabular}

${ }^{1}$ Whereby 1 indicates most deprived region. Total rank out of 32482 in England
Results Eighty-nine patients with Liverpool postcodes were included in the study. Number of DNAs ranged from 1 to 6 . Data according to patient group by number of DNAs is displayed below. Only two patients had missed 5 and 6 appointments therefore these groups were excluded from analysis. There was no statistical difference between distance from hospital, time to get to hospital by public transport or socioeconomic status on the number of missed appointments. See Table 1.

Discussion Reasons for missing clinic appointments are multifactorial and, in our cohort, there was no association found between distance from the hospital, time taken by public transport to reach the hospital or economic deprivation. Assumptions of low socioeconomic status relating to poor clinic attendance are often made by clinicians however there is no evidence to suggest this is valid in our patient group. Reducing DNA's remains an important area of investigation and a key objective of NHS Institution of Innovation and improvement.

\section{REFERENCES}

1. Gibson, PG, Powel H, Coughlin J, et al. Self management education and regular practitioner review for adults with asthma Cochrane Database Syst Rev 2003;(1): CD00117

2. Hamilton, W., Round, A. \& Sharp, D. Patient hospital and general practitioner characteristics associated with nonattendance: a cohort study. British Journal of General Practice. 2002; (314) 317-319.

3. English Indices of Deprivation 2010, Department for Communities and Local governments March 2011, Available from www.gov.uk/governemtn/publications/englishindices-of-deprivation-2012

\section{M9 THE PREVALANCE AND EFFECTS OF SMOKING AMONGST PATIENTS ATTENDING A DIFFICULT ASTHMA CLINIC}

${ }^{1}$ DWY Ding, ${ }^{1} \mathrm{P}$ Abraham, ${ }^{2} \mathrm{RK}$ Yadavilli, ${ }^{1} \mathrm{BJ}$ McDonough, ${ }^{1} \mathrm{~S}$ Mault, ${ }^{1} \mathrm{H}$ Burhan; ${ }^{1}$ Royal Liverpool University Hospital, Liverpool, United Kingdom; ' ${ }^{1}$ nniversity Hospital Aintree, Liverpool, United Kingdom

\subsection{6/thoraxjnl-2013-204457.419}

Introduction The proportion of asthmatics that smoke is no different to that in the general population ${ }^{1,2}$. In patients with asthma, smoking has been associated with decline in pulmonary function, poor symptom control and reduced quality of life.

Objectives To evaluate the differences in lung function, number of asthma admissions in the previous year, asthma control, quality of life and treatment between non-smokers, ex-smokers and current smokers attending an asthma clinic. Methods: Retrospective study of 92 patients from a dedicated asthma clinic. Patients

\section{Abstract M9 Table 1.}

\begin{tabular}{|c|c|c|c|c|}
\hline & $\begin{array}{l}\text { Non-Smoker } \\
(\mathrm{n}=66)\end{array}$ & $\begin{array}{l}\text { Ex-Smoker } \\
(\mathrm{n}=17)\end{array}$ & $\begin{array}{l}\text { Current Smoker } \\
(\mathrm{n}=9)\end{array}$ & ANOVA / Chi-squared test \\
\hline FEV1 & $2.3 \pm 0.1$ & $2.0 \pm 0.2$ & $1.8 \pm 0.2$ & $F(2,89)=1.83, p=0.17$ \\
\hline FEV1\% & $85.3 \pm 2.7$ & $79.1 \pm 5.8$ & $66.5 \pm 6.7$ & $F(2,89)=3.14, p=0.048$ \\
\hline FVC & $3.2 \pm 0.1$ & $3.0 \pm 0.2$ & $3.1 \pm 0.3$ & $F(2,89)=0.45, p=0.64$ \\
\hline FVC\% & $100.9 \pm 2.6$ & $94.9 \pm 5.8$ & $99.4 \pm 5.8$ & $F(2,89)=0.55, p=0.58$ \\
\hline FEV1/FVC ratio & $71.8 \pm 1.3$ & $68.7 \pm 3.1$ & $59.2 \pm 4.8$ & $F(2,89)=5.00, p=0.009$ \\
\hline $\begin{array}{l}\text { Number of hospital admissions with asthma } \\
\text { in the preceeding year }\end{array}$ & $1.0 \pm 0.1$ & $1.2 \pm 0.4$ & $1.2 \pm 0.4$ & $\chi^{2}=13.1, d f=12, p=0.36$ \\
\hline AQLQ score & $3.8 \pm 0.2$ & $3.4 \pm 0.3$ & $3.8 \pm 0.5$ & $\chi^{2}=79.3, d f=98, p=0.92$ \\
\hline ACT score & $13.6 \pm 0.7$ & $12.5 \pm 1.0$ & $11.1 \pm 1.9$ & $\chi^{2}=38.2, d f=40, p=0.55$ \\
\hline BTS step in Asthma & $3.8 \pm 0.1$ & $3.6 \pm 0.2$ & $3.4 \pm 0.3$ & $\chi^{2}=10.3, d f=8, p=0.25$ \\
\hline Management & & & & \\
\hline
\end{tabular}

